\title{
Pesquisa Participante: Alteridade e COMUNIDADES INTERPRETATIVAS ${ }^{1}$
}

\author{
Maria Luisa Sandoval Schmidt ${ }^{2}$
}

Instituto de Psicologia - USP

Este artigo apresenta um conjunto de problemas postos à pesquisa que busca a colaboração de indivíduos, grupos e coletividades cuja experiência, pessoal e coletiva, se quer conhecer. Apoiando-se nas matrizes etnográficas da pesquisa participante em Antropologia, focaliza a política e a ética da pesquisa de campo como diálogo de identidades/alteridades e seus nexos com a constituição de comunidades interpretativas.

Descritores: Pesquisa participante. Etnografia. Alteridade. Comunidades interpretativas.

- 7 1995, Boaventura de Sousa Santos (1999) publicou o artigo "Da idéia Cde universidade à universidade de idéias", no qual analisava as crises de hegemonia, de legitimidade e institucional das universidades modernas, apresentando, ao final, uma pauta de transformações, em sua opinião, necessárias a uma digna sobrevivência destas instituições na chamada pós-modernidade.

Mutuamente implicadas, as crises de hegemonia, de legitimidade e institucional vêm se instalando nas universidades desde o final da Segunda Guerra Mundial e uma breve referência às suas características gerais concorre para uma melhor compreensão das propostas para seu enfrentamento sugeridas pelo autor e que interessam, particularmente, à discussão sobre o papel da pesquisa participante.

1 Este texto foi apresentado, originalmente, como ensaio na tese de livre docência Ensaios indisciplinados: aconselhamento psicológico e pesquisa participante, defendida em agosto de 2005, junto ao Instituto de Psicologia da Universidade de São Paulo.

2 Docente do Departamento de Psicologia da Aprendizagem, do Desenvolvimento e da Personalidade do Instituto de Psicologia - USP. Endereço para correspondência: Rua Capote Valente, 964, apto11, São Paulo, SP. CEP 05409-002. Endereço eletrônico: maluschmidt@terra.com.br 
A crise de hegemonia descreve a perda do domínio e, até certo ponto, da exclusividade da universidade na produção e transmissão do conhecimento que passa a ser requerido, também, na esfera da formação profissional, competindo, por um lado, com outras instituições profissionalizantes de ensino superior e, por outro, com a emergência de uma cultura média veiculada pelos meios de comunicação de massa.

A crise de legitimidade, por sua vez, expõe as contradições entre a intensa hierarquização dos saberes especializados que pede competências restritivas ao acesso e ao credenciamento para o ensino universitário e as exigências societárias de democratização das oportunidades de ingresso neste ensino.

Por fim, a crise institucional reside, principalmente, na tensão entre a reivindicação da autonomia universitária na definição de seus valores e objetivos e a pressão para que se submeta a critérios produtivistas e empresariais (Santos, 2004).

No texto de 1995, Boaventura de Sousa Santos ateve-se a considerações sobre as universidades públicas e buscou mostrar que estas, "longe de poder resolver as suas crises, tinham vindo a geri-las de molde a evitar que elas se aprofundassem descontroladamente" (Santos, 1999, p. 9). A ação das universidades frente às crises era, e em grande parte continua sendo, reativa, acrítica e imediatista, dispensado a reflexão sobre projeções de médio ou longo prazo.

Contra esta tendência de responder no curto prazo a problemas de fundo que ameaçam a própria sobrevivência das universidades, o autor propôs, ao finalizar sua análise, um conjunto de teses que, como micro-utopia, investem no médio e longo prazo, sem os quais entende que, "a curto prazo, a universidade só terá curto prazo" (Santos, 1999, p. 230).

Destas teses, destacam-se, aqui, duas, cujos argumentos servem de base à discussão sobre o lugar da pesquisa participante na micro-utopia de uma universidade democrática e emancipatória. São elas: 1) a necessidade de uma dupla ruptura, por um lado, com o paradigma positivista de ciência e, por outro, com a hegemonia do saber científico em relação a outros saberes como o senso comum e a sabedoria popular; 2) a idéia de que a democratização da universidade, embora passando pela transformação das estruturas de poder 
internas e pela ampliação do acesso ao ensino superior, depende, sobretudo, da criação de comunidades interpretativas que integrem o conhecimento científico, o pensamento do senso comum, os saberes populares e a mídia para um confrontamento dos problemas sociais em nível local, nacional ou internacional.

A ruptura com o paradigma positivista e com a hegemonia do saber científico enseja o debate epistemológico e metodológico em torno da pes-

quisa em ciências humanas. A idéia de comunidades interpretativas faz apelo a uma democratização do saber não apenas em seu momento de divulgação e "aplicação", mas, além disso, na ordem de sua constituição ou produção. A prática da pesquisa participante é capaz de aglutinar em torno de si tanto a reflexão epistemológica que interessa à ruptura com o paradigma positivista quanto a apreensão crítica das dimensões éticas e políticas das pesquisas de campo, configurando metodologias que promovem uma relação com o outro próxima à idéia de comunidades interpretativas.

Esta pertinência da pesquisa participante como ensaio ou exemplo do horizonte utópico no qual a universidade pode se projetar não chega a ser explicitado por Boaventura de Sousa Santos, no texto de 1995. Em 2004, porém, ao retomar o assunto da crise universitária, tendo em vista apresentar sua contribuição para uma reforma democrática e emancipatória, a pesquisa participante é citada, pelo autor, como prática pertinente à reforma, sem, contudo, receber um tratamento mais detalhado.

Fazer, na medida do possível, uma explicitação dos nexos entre a alteridade na pesquisa participante e as comunidades interpretativas, visando a contribuir para o debate sobre a democratização e a reforma da universidade, é a intenção deste ensaio.

\section{Pesquisa participante, pesquisas participantes}

A pesquisa participante abriga um sem-número de discursos e práticas de pesquisa qualitativa em ciências humanas: matrizes e modelos de pesquisa reivindicam o termo que, historicamente, foi se desdobrando em tendências ou linhas teórico-metodológicas que, embora aparentadas, apresentam singularidades que as distinguem. 
Uma cartografia destas singularidades exigiria o exame das representações de ruptura e continuidade em relação às matrizes da pesquisa etnográfica que, na virada do século XIX para o XX, fundam a Etnografia e, portanto, a pesquisa participante, como disciplina científica. Autores como James Clifford (2002) ou George E. Marcus (1998), entre outros, fazem interpretações minuciosas e profícuas destas matrizes antropológicas e seus desdobramentos históricos.

Embora seja tentador penetrar nas ramificadas sendas da história da Antropologia, buscando um maior esclarecimento sobre os caminhos da pesquisa participante, para o tratamento dos temas e das questões que aqui serão propostos basta, talvez, a indicação, esquemática certamente, de dois modos de relação com a tradição etnográfica na configuração de pesquisas participantes: linhas teórico-metodológicas que se constituem por oposição à tradição etnográfica, supondo-se a si mesmas como descontinuidades críticas e inovadoras e tendências que retomam os problemas postos pelas práticas inaugurais no e do interior de pesquisas etnográficas. Estes modos, parece, ajudam a identificar, por um lado, peculiaridades e diferenças atribuídas às chamadas pesquisa-ação e pesquisa-intervenção que têm um largo trânsito na Psicologia e, por outro, a situar a pesquisa participante como pesquisa etnográfica. Mais ainda, ajudam a problematizar a dicotomia ruptura/continuidade, procurando mostrar que há continuidades na ruptura e rupturas na continuidade.

O pensamento de ruptura tende, neste caso, a ver a tradição como depositária de todas as práticas, atitudes, valores e idéias que se quer combater por meio da novidade de práticas, atitudes, valores e idéias que este pensamento motiva.

O termo participante sugere a controversa inserção de um pesquisador num campo de investigação formado pela vida social e cultural de um outro, próximo ou distante, que, por sua vez, é convocado a participar da investigação na qualidade de informante, colaborador ou interlocutor. Desde as primeiras experiências etnográficas, pesquisador e pesquisado foram, para todos os efeitos, sujeitos e objetos do conhecimento e a natureza destas complexas relações estiveram, e estão, no centro das reflexões que modelam e matizam as diferenças teórico-metodológicas.

O antagonismo da ruptura tende, por vezes, a simplificar a visão de alteridade e a capacidade auto-reflexiva dos etnógrafos clássicos; a adesão burocrática a protocolos de pesquisa consagrados tende a obscurecer ou mesmo 
negar a necessária negociação envolvida no encontro com o outro, bem como a necessária apreensão de si mesmo na relação com o outro.

Se o termo pesquisa participante pode abrigar o plural e o diverso que a compõem é porque pode abrigar a diversidade e a pluralidade de modos de viver e pensar a alteridade e a auto-reflexão na produção do conhecimento sobre a diversidade humana. Posicionar-se em relação a este campo de diferenças é, por essa razão, participar do interjogo de alteridades e identidades que conformam cada maneira de pesquisar.

A posição que se quer abraçar ou clarear para conduzir a discussão sobre temas e idéias capazes de articular pesquisa participante, alteridade e comunidades interpretativas passa por um comentário sobre a pesquisa-ação e a pesquisa-intervenção por comparação, confronto e complementação à pesquisa etnográfica.

A pesquisa-ação é exemplificada pela posição de Carlos Rodrigues Brandão para quem a Antropologia inventou um método participante, a observação participante, sem que, contudo, tivesse se tornado, ela mesma, politicamente participante. Sob a influência do marxismo, a observação participante que buscava "conhecer para explicar" o outro transmuta-se em pesquisa participante, procurando, então, “compreender para servir". Convivência e compromisso articulam-se para dar sentido a uma prática científica que participa do trabalho político das classes populares (Brandão, 1999).

As idéias de ação ou intervenção não são equivalentes, mas sugerem, além da presença do pesquisador como parte do campo investigado, a presença de um outro que, na medida em que participa da pesquisa como sujeito ativo, se educa e se organiza, apropriando-se, para a ação, de um saber construído coletivamente. A alteridade é visada como co-produtora da mudança social e convocada à participação e o pesquisador é obrigado a questionar sua pesquisa e sua pessoa na direção de um engajamento político com a luta popular. Neste ponto, segundo Brandão, a pesquisa participante é propriamente inventada e rompe, até certo ponto, com a tradição etnográfica inaugurada pela Antropologia que, embora "mergulhasse" no mundo do outro, desobrigava-se "das questões efetivamente sociais das condições de vida dos outros" (Brandão, 1999, p. 12).

Abordando uma outra linha de filiações, na área da Psicologia, Rocha e Aguiar (2003) apontam Kurt Lewin como o iniciador das pesquisas de cam- 
po de feição da pesquisa-ação e da dinâmica de grupo, voltadas para os problemas de ajustamento de populações marginais, para a resolução de conflitos no trabalho ou em situações de tensão interpessoal, implicando na intervenção concreta na realidade.

Se Brandão identifica nas experiências etnográficas a persistência da cisão sujeito/objeto separando pesquisadores e informantes, estes últimos colocados no lugar de objetos de estudo, as autoras, sondando a história da pesquisa-intervenção, encontram, em Lewin, a mesma cisão entre sujeito e objeto, bem como a naturalização da ordem social na qual os conflitos e crises são interpretados como disfunção e desordem. A intervenção, nesse caso, visava ao restabelecimento da ordem (capitalista), apartando-se de uma inclusão dos sujeitos da pesquisa como possíveis agentes de mudança social.

A pesquisa-intervenção, que as autoras definem como "uma proposta de atuação transformadora da realidade sócio-política", é devedora da crítica a Lewin empreendida pelo movimento de pesquisa-ação na América Latina que, a partir dos anos 60, elabora projetos auto-gestionados de mudança social e filia-se às correntes institucionalistas da Psicologia.

Nucleares nesta proposta são as metodologias coletivas e a produção cooperativa, "quebrando" as hierarquias burocráticas das instituições e as divisões por especialidades. A neutralidade e a objetividade do pesquisador são questionadas, bem como a gênese teórica e social dos interesses de pesquisa (Rocha \& Aguiar, 2003).

Nestes dois exemplos, repete-se, de alguma maneira, a referência a uma contingência da pesquisa de campo, em Antropologia e em Psicologia Social, que coloca frente a frente o pesquisador e um outro que, de objeto de estudo e de intervenção passa à condição de sujeito de um conhecimento e agente de uma transformação social que a prática da pesquisa participante propicia. A pesquisa participante, nestes casos, é tomada como uma referência histórica que se radicaliza teórica e metodologicamente tanto no questionamento da participação do pesquisador quanto na implementação da participação de grupos institucionais e/ou comunidades populares no planejamento e condução de pesquisas que visam à ação transformadora de coletivos. Não há o rompimento com a designação pesquisa participante mas, talvez, a necessidade de marcar uma posição crítica sobre suas origens por meio da adoção de 
novas terminologias, pesquisa-ação e pesquisa-intervenção, nas quais a questão do agir coletivo se torna essencial.

Michel Thiollent (1999), autor de referência no debate sobre metodologias qualitativas em ciências humanas, faz a distinção entre pesquisa participante e pesquisa-ação, valendo-se desta identificação da pesquisa participante com o modelo da observação participante praticado nas experiências inaugurais da investigação antropológica e etnográfica. Assim, se, por um lado, a pesquisa-ação constitui-se num tipo de pesquisa participante porque, em alguma medida, se serve da observação participante "associada à ação cultural, educacional, organizacional, política ou outra", por outro, dela se separa quando focaliza "a ação planejada, de uma intervenção com mudanças dentro da situação investigada", priorizando a participação do pólo pesquisado (Thiollent, 1999, pp. 83-84). Este argumento confina a pesquisa participante à esfera da observação participante que, para este autor, tratava de criar e "aperfeiçoar" os dispositivos que facilitassem a inserção do pesquisador no cotidiano habitual dos grupos pesquisados, com a finalidade de "observar fatos, situações e comportamentos que não ocorreriam ou que seriam alterados na presença de estranhos" (Thiollent, 1999, p. 83).

As noções de ação e intervenção que conferem especificidade teórica e metodológica a um tipo de pesquisa participante que se divorcia politicamente dos propósitos da matriz antropológica e etnográfica não esgotam os desdobramentos desta matriz no questionamento das relações entre "o pólo pesquisador e o pólo pesquisado". E, mesmo, é possível que estas matrizes, lidas sob certa perspectiva, interroguem, criticamente, tais noções de ação e intervenção, pois não deixa de ser uma pretensão do pesquisador - psicólogo, sociólogo, educador ou antropólogo - achar que um grupo ou uma classe social necessita de sua ajuda para agir politicamente, criar cultura e educar-se para a consciência de seus direitos. Há uma espécie de respeito pelo outro que se concretiza no interesse por seus modos de viver, sentir e pensar, sem cobrar que ele seja o que não é.

Esta observação vem só para reforçar a tese de que assim como a pesquisa-ação e a pesquisa-intervenção realizam uma crítica do caráter relativamente objetivante das experiências etnográficas, as experiências etnográficas, por sua vez, oferecem argumentos críticos relevantes para uma avaliação dos propósitos destes modos de pesquisar. Porém, os principais motivos para fa- 
zer uma referência menos simplificadora às etnografias "modelares" são, por um lado, mostrar que alteridade e auto-reflexividade estiveram ali presentes, tensionando objetividade e subjetividade e construindo pontes entre o trabalho de campo e a escrita etnográfica. Por outro lado, explicitar o contexto em que objetivos, procedimentos, textos e compromissos do trabalho etnográfico aparecem como problemas pertinentes à pesquisa participante que se quer parceira da democratização da universidade e da sociedade.

As noções de ação e intervenção não parecem ter o monopólio da crítica epistemológica e metodológica que vem transformando a pesquisa participante e a explicitação das mais radicais consequiências da presença do pesquisador em campo e da consciência da alteridade deve muito ao trabalho etnográfico que faz justiça a uma tradição sem, contudo, apenas repeti-la.

\section{Matrizes etnográficas}

James Clifford (2002), no livro A experiência etnográfica, escreve dois instigantes ensaios sobre dois antropólogos, Malinowski e Griaule, cujas experiências, por caminhos diferentes, estão ligadas à fundação da disciplina antropológica. Não são as únicas experiências a se destacar na tentativa de abrir a discussão sobre alteridade pelo viés da pesquisa etnográfica. São, contudo, experiências matriciais que, conduzidas pela sensível interpretação de Clifford, permitem uma visão da problemática e rica empreitada que é o encontro etnográfico.

No ensaio sobre Bronislaw Malinowski, Clifford parte da idéia, para ele inquestionável, de que a individualidade é articulada no interior de mundos de significação que são coletivos e limitados para, então, perguntar sobre como é possível historicizar a idéia de que o eu é construído culturalmente. Recorre, então, à história da Antropologia.

Na virada do século XIX para o XX, localiza-se o projeto de uma Antropologia do indivíduo e da singularidade cultural, projeto que se opõe à anterior tendência de buscar a universalidade do homem nos estudos comparativos das diferentes culturas. É, ainda, nesta virada de séculos que a Antropologia moderna se institui como ciência. 
A “cientifização" da Antropologia corresponde à profissionalização da observação participante. Segundo Clifford (2002):

A antropologia moderna - uma ciência do homem intimamente relacionada à descrição cultural - pressupunha uma atitude irônica de observação participante. Ao profissionalizar o trabalho de campo, a antropologia transformou uma situação amplamente difundida num método científico. (p. 102)

Inaugura-se a dialética de construção interpretativa de um outro que é constituído culturalmente, construção interpretativa que implica a identidade de um intérprete de outra cultura.

A identidade do intérprete autorizado profissionalmente como antropólogo ou etnógrafo é modelada: quando retrata outros eus como culturalmente constituídos, o intérprete "modela uma identidade autorizada a representar, a interpretar, e mesmo a acreditar - mas sempre com alguma ironia - nas verdades de mundos discrepantes" (Clifford, 2002, p. 103). Para Clifford, Malinowski encarna a experiência de modelagem de um intérprete com autoridade para compreender o outro em nome da cultura ocidental européia.

A experiência de Malinowski, além de ser "uma espécie de carta fundadora da antropologia do século XX", é exemplar no embate com a linguagem e com a cultura na tentativa de construir e manter uma identidade num espaço de "entre mundos", a cultura européia e a cultura trobriandesa.

Trata-se da dupla tarefa de, por um lado, lutar contra a dissolução da identidade do pesquisador imerso na solidão e no caráter multivocal do trabalho de campo e, por outro lado, da construção crível de uma imagem do mundo do outro. É preciso, ao mesmo tempo, preservar a coerência pessoal e articular coerentemente os achados incompletos e contraditórios do trabalho de campo.

Nesse processo, Clifford atribui lugar de destaque ao papel da escrita. Em sua visão, a escrita resgata Malinowski da desintegração e da depressão, dando a oportunidade de assentar as diferentes verdades dos diversos discursos e acontecimentos com os quais se depara no trabalho de campo. A unificação, da identidade do pesquisador e dos achados do campo, acontece pela escrita na qual o pesquisador, como uma espécie de diretor de cena, seleciona, combina, reescreve e apaga textos. 
Ao focalizar a escrita, Clifford aponta o caráter construtor do texto etnográfico: mais do que complementar ao trabalho de campo, o texto vem a ser, ainda, um substituto para o "anseio de uma interlocução sincera” (2002, p. 122).

A edição do texto etnográfico que finalmente vem a público constrói e reconstrói "coerentes outros culturais e eus interpretativos". Esta qualidade do texto etnográfico revela algumas características fundamentais do conhecimento em ciências humanas: sua historicidade e seu cunho parcial. Citando Clifford (2002):

(...) as verdades das descrições culturais são significativas para específicas comunidades interpretativas em determinadas circunstâncias históricas. Assim, o "arrancar" ou "rasgar", lembra-nos Nietzsche, é simultaneamente um ato de censura e de criação de significado, uma supressão de incoerência e contradição. As melhores ficções etnográficas são, como a de Malinowski, intricadamente verdadeiras; mas seus fatos, assim como todos os fatos nas ciências humanas, são classificados, contextualizados, narrados e intensificados. (p. 126)

A marca construtora do texto etnográfico é visível na projeção de identidades e alteridades e como mediadora de "mundos discrepantes de significado". Nesse sentido, para a pesquisa participante que busca a compreensão do outro, o texto tem o mesmo valor que têm a ação ou a intervenção para aquela que busca a conscientização ou a organização política do outro.

A escrita etnográfica produz efeitos de reconhecimento e desconhecimento do outro, bem como de dominação e controle da experiência de campo, em benefício da arquitetura coerente das representações da alteridade e da constituição identitária de um intérprete legitimado.

Em Malinowski, duas "experimentações específicas com a escrita", o livro Os argonautas do Pacífico Ocidental (1978) e Um diário no sentido estrito do termo (n.d.), permitem uma aproximação das tensões e complexidades do encontro etnográfico: no primeiro, aparece a descrição da cultura trobriandesa, do ponto de vista da instituição do Kula; no segundo, uma explosão polifônica dos sentidos pessoais e subjetivos da vivência do pesquisador.

Para Clifford (2002), o diário de Malinowski obriga a enfrentar a complexidade dos encontros etnográficos e a "tratar todos os relatos textuais baseados em trabalho de campo como construções parciais” (p. 107). 
Estas construções parciais ingressam no mundo como condutoras significativas de representações da alteridade e da diversidade cultural, estabelecem pontes ou mediações entre diferentes universos de vida social e o fazem desde um ponto de vista teórico e metodológico que é, ao mesmo tempo, político-ideológico.

O informante é o veículo para a objetivação de uma cultura nos termos de um sistema coerente de símbolos e práticas. Por isso, como transparece no diário de Malinowski, o informante é menos e mais do que um objeto de estudo: menos, porque não é dele que se trata, mas de sua cultura; mais, porque é preciso conversar com ele, convencê-lo a colaborar, negociar posições e informações, aguardá-lo, entender o que ele diz e assim por diante. Este foi só um dos "problemas" que Malinowski teve que enfrentar: estar diante de um objeto de estudo que dependia de informantes com vontade própria, situados em seu próprio lugar de vida.

O intento de dominar e controlar o trabalho de campo é, também, o intento de dominar e controlar o informante, fazendo com que ele convirja para os objetivos da pesquisa. O mesmo desejo de domínio e controle recai sobre o pesquisador que, por meio do método, procura moldar-se como instrumento fidedigno e confiável de observação e interpretação do outro. Esta é a política da pesquisa de campo de Malinowski.

No plano ideológico, paradoxalmente, talvez, é a construção da cultura trobriandesa desde a perspectiva dos nativos que está em jogo: o pesquisador procura decifrar ou desvendar "objetivamente" os significados e a lógica das concepções e práticas nativas. Concomitantemente, como já se disse, trava o combate moral e psicológico de preservação de si como um outro que quer conhecer, sem se perder.

Nesta relação pesquisador/pesquisado percebe-se a presença de dimensões negadas ou enquadradas em nome do método científico que então buscava uma fundação segura na esfera das ciências humanas: no informante, nega-se o valor do colaborador ou do interlocutor na construção do conhecimento ou na interpretação da cultura; no pesquisador, o valor da auto-reflexibilidade como componente desta construção. 
A experiência de Marcel Griaule contrasta com a de Malinowski em muitos aspectos: no uso de diferentes métodos de documentação - textos, fotografias, mapas e objetos - e de diferentes observadores por meio da investigação em equipe; no prolongado contato com a cultura dogon, marcado por uma fase de intensa pesquisa documental seguida de uma experiência de "iniciação"; pela inclusão de informantes, tradutores e autoridades tribais como agentes ativos na pesquisa (Clifford, 2002).

O controle político e científico do encontro etnográfico apresenta-se bem mais complicado no contexto de um trabalho de campo em equipe composta por especialistas europeus que, pouco a pouco, incorpora uma rede de colaboradores nativos. A pesquisa documental, nesse sentido, é particularizada pela busca de um controle envolvendo negociações dos interesses dos pesquisadores e dos nativos e o estabelecimento de vários e diferentes pontos de observação e de verificação das informações. Mas, na medida em que se intensifica o respeito de Griaule pela tradição oral africana, sua pesquisa concentra-se "num trabalho interpessoal com um número limitado de colaboradores indígenas" (Clifford, 2002).

$\mathrm{Na}$ análise de Clifford, destaca-se o estilo pessoal de Griaule como parte integrante da atividade de pesquisa e como um modo próprio de responder à violência subjacente às relações entre brancos e negros na situação colonial e à característica de intrusão de sua pesquisa, dando forma a uma escrita provocativa e a uma investigação provocadora.

Embora em Griaule, assim como em outros "pioneiros" da Antropologia, não existam registros mais evidentes sobre a dinâmica interpessoal ou sobre a política da pesquisa, seus textos não se privam de expor constrangimentos e pressões por ele impostos aos nativos em benefício de suas investigações, bem como, em algumas passagens, denunciam a presença de tensões políticas e éticas. Ao finalizar a transcrição das conversações com Ogotemmêli - velho caçador cego que expõe ao longo de trinta e três jornadas sua versão da cosmologia dogon -, Griaule (2000) escreve:

Pensando en estas incomprensiones voluntarias (sobre o papel civilizatório das culturas africanas), en estas negativas a conocer, el blanco sentía cierta vergüenza ante el cortés ciego que iba a dejar al día siguiente. Hubiera querido expresar todo su homenaje a este hombre privado de luz y cuya palavra, según decía, era luz. Hubiera querido excusarse por todos los desprecios de Europa y América, por tanta ignorancia. (p. 205) 
Considerando a cultura como performance, espetáculo, Griaule servese dos papéis e lugares designados pela Etnografia liberal da época colonialista para observar e documentar a cultura dogon, acumulando um conhecimento que irá se aprofundar a partir da mudança de postura que corresponde à fase de sua iniciação. Nesta fase, o pesquisador, que antes descrevia e documentava a cultura nos termos quase de um inquérito, desliza para a posição de transcritor do saber formulado, tradutor, exegeta e comentador. $\mathrm{O}$ informante, por sua vez, passa à posição de professor ou instrutor.

No parâmetro iniciático, a narrativa de iniciação confirma a competência do pesquisador que textualiza o sistema tradicional de conhecimento dos dogon, dando oportunidade a uma reinscrição da ordem mítica numa escala mundana (Clifford, 2002).

Para Clifford, à guisa de conclusão desde comentário sobre a experiência etnográfica de Griaule:

O paradigma de Griaule funcionou para transformar o papel do etnógrafo de observador e documentador da cultura dogon em exegeta e intérprete. Ele preservou e reformulou, no entanto, os temas dominantes de sua prática: a lógica do segredo, uma aspiração a um conhecimento exaustivo, uma visão do trabalho de campo como desempenho de papéis. Esse paradigma expressou também o sentimento, que se tem ao longo da carreira de Griaule, de que seus parceiros dogon foram poderosos agentes do processo etnográfico: inicialmente, exibindo táticas brilhantes e resistência voluntariosa; depois, como professores e colegas. (Clifford, 2002, p. 219)

Estas duas experiências exemplares, brevemente referidas, são suficientes para mostrar como o projeto de "cientifização" da observação participante singulariza-se nestes encontros etnográficos: as normas metodológicas, quando confrontadas com a realidade do trabalho de campo e com a presença concreta e ativa do outro, tornam-se instáveis, precárias, como provam o atormentado diário de Malinowski e as críticas recebidas por Griaule em razão de suas heterodoxias metodológicas.

A crença realista nas descrições objetivas das culturas e a constituição identitária do pesquisador profissional estão intimamente ligadas, na fundação da Antropologia científica, à busca de objetivação da observação participante. Porém, em suas "falhas", insinua-se a problemática do interjogo de identidades e alteridades na configuração dos lugares de pesquisador e pesquisado e a 
tarefa auto-reflexiva que, na continuidade histórica da Antropologia, questiona tal crença e tal identidade.

A passagem, se assim se pode dizer, de uma Antropologia realista "clássica", localizada entre o final do século XIX e princípio do século XX - a uma Antropologia modernista - contemporânea, "filha" da Antropologia interpretativa dos anos 60 e 70 - deve muito ao quase desaparecimento das sociedades "exóticas"3 relativamente isoladas e "preservadas" do início da Antropologia científica e às mudanças, em escala mundial, da dinâmica do contato intercultural e suas ressonâncias na diversidade e mobilidade das identidades de indivíduos, grupos e coletividades.

Para Marcus e Fischer (1986), a Antropologia interpretativa toma a Etnografia clássica como referência para uma atualização da pesquisa participante baseada no trabalho de campo e na escrita do texto etnográfico, discutindo, por um lado, a aspiração das etnografias realistas de elucidar o ponto de vista do nativo e, por outro, os processos de comunicação no trabalho de campo por meio dos quais os antropólogos se autorizavam a representar outros sistemas culturais em seus textos.

A escrita etnográfica experimental, consequiência da revisão feita pela Antropologia interpretativa, lê os clássicos buscando suas possibilidades latentes, legitimando-se e se renovando na medida em que se localiza em relação à tradição da escrita etnográfica. O experimento é tido como uma reorientação e não como rompimento com a tradição etnográfica (Marcus e Fischer, 1986). Interessante neste liame com a tradição é a retomada crítica de temas reconhecidos no passado mas ignorados ou excluídos pela predominância de outras idéias em que estava mergulhado um certo "cientificismo".

O contexto e a natureza desta reorientação em relação à tradição importam sobremaneira à clarificação de um modo de teorizar e praticar a pesquisa

3 Marc Augé (1997) escreveu o seguinte sobre o fim do exotismo: “... certamente há sempre sociedades longínquas (do ponto de vista europeu) e há sempre 'minorias' cujos modos de vida e de pensamento podem estimular mais particularmente o interesse ou às vezes a agressividade daqueles que compõem a "maioria"; mas o exotismo está, definitivamente, morto ou morrendo. (...) Hoje o Planeta encolheu, a informação e as imagens circulam e, ao mesmo tempo, a dimensão mítica dos outros se apaga. Os outros não mais são diferentes: mais exatamente a alteridade permanece mas os prestígios do exotismo desapareceram" (p. 26). 
participante que, focalizando a interpretação dos sentidos ou significados da vida social, acaba por focalizar o próprio encontro etnográfico como processo de construção de significados e, portanto, de conhecimento.

O contexto pode ser descrito, como faz Marcus (1998), por meio do crescente interesse dos estudos antropológicos mais recentes pelos processos de negociação, composição e transformação das identidades de indivíduos, grupos e coletividades marcados por uma espécie de dispersão ou multiplicação de espaços e tempos.

Ou, como prefere Marc Augé (1994), num entendimento mais amplo, pela supermodernidade caracterizada pelo encurtamento dos espaços, pela aceleração do tempo ou da história e pela individualização.

Trata-se, em ambos os casos, do contexto do mundo contemporâneo em que o contemporâneo dilata-se numa pluralidade de mundos coexistentes e conectados, mundos definidos pelo paradoxo de exprimirem, ao mesmo tempo, " a singularidade que os constitui e a universalidade que os relativiza” (Augé, 1997, p. 143).

A complexidade contemporânea, feita do cruzamento de mundos por onde passam as relações de sentido, as identidades e as alteridades instituídas e simbolizadas, apresenta-se como um desafio ao trabalho etnográfico.

Augé (1997) demarca o problema dos processos de formação identitária, enlaçando identidade, alteridade e sentido numa mesma crise à qual a Antropologia é convocada a revidar. Para ele, o encurtamento das distâncias entre próximo e longínquo é acompanhado de reações como xenofobia, racismo, crise de identidade que tendem a cristalizar ou tornar não simbolizável o outro. Se a identidade é construída por oposição ou comparação com o outro, toda crise de identidade é, também, uma crise de alteridade. E, toda crise de alteridade é uma crise de sentido, crise que a Antropologia é invitada a estudar.

O contexto aponta um desafio e este, por sua vez, é encarado pela Etnografia experimental, modernista, que, buscando seguir as migrações e dispersões das singulares formações identitárias, torna-se, ela mesma, permeável às vicissitudes de seu objeto de estudo.

Se, como afirma Marcus (1998), os sujeitos/identidades que são o outro que se quer conhecer estão desmanchando no ar, então a identidade do et- 
nógrafo não pode permanecer sólida e intata no estudo destes outros. O cenário da procura de um sentido do outro é solidário àquele da procura do sentido da pesquisa etnográfica. Por isso, a qualidade de seus experimentos é crítica, tornando mais explícitas metodologias participantes ética e politicamente sensíveis às mútuas implicações do par identidade/alteridade.

Alguns traços comuns a estes experimentos são reconhecíveis e cabe aqui nomeá-los.

Primeiramente, é preciso admitir o quase desaparecimento dos "lugares tradicionais" da investigação antropológica e, mesmo, mais recentemente, da antropologia de urgência (estudo de certos povos "em vias de desaparecimento"). ${ }^{4}$ Isto indica outras e novas localizações da Etnografia contemporânea: as cidades, os novos movimentos religiosos, as regiões de fronteira, entre outras. Com isso, o outro, outrora distante no espaço e exótico, pode ser, agora, o habitante de uma mesma cidade ou bairro, o adepto de formas de religiosidade idiossincráticas ou o imigrante. Trata-se, na verdade, da multiplicação de outros, próximos e distantes, da aproximação do distante e do distanciamento do próximo, da possibilidade do outro alhures e do outro aqui.

Sobre a relação entre teoria e empiria, Augé (1997) avalia que na situação atual a imposição do trabalho de campo à teoria é mais visível do que o inverso, ou seja, um enquadramento teórico das descobertas do campo, como era mais comum em tempos atrás. Esta observação de Augé é complementar à interessante pontuação de Marcus (1998) sobre o quanto a mudança dos conceitos do pesquisador é mais importante do que a mudança dos conceitos de seus interlocutores, na pesquisa de campo empreendida no espírito experimental. $\mathrm{O}$ trabalho de campo, nesta perspectiva, serve menos à confirmação das teorias antropológicas e mais ao teste dos limites e das insuficiências dos conceitos familiares aos antropólogos. As relações entre mundo e experiência, texto e realidade, estrutura e ação tornam-se discutíveis e não há nenhuma teoria social dada ou tradicional capaz de colocar em ordem os paradoxos da homogeneização/diversificação, da localização/globalização e da singularização/universalização. Os desenhos metodológicos das pesquisas de campo,

4 Há, nesta observação, uma grande dose de ironia, pois para uma certa militância antropológica haveria grupos ou povos nativos "puros" que, pelo contato com outras culturas, tenderiam a desaparecer, ou seja, a perder sua "autenticidade original". 
bem como sua teorização, fragmentam-se e se multiplicam em sintonia com as singularidades de cada mundo estudado que, no entanto, em si, não serve como referência ou modelo unificador.

A chave para a crítica modernista é a procura de possibilidades da identidade e suas complexas expressões, confrontando a hegemonia de certas representações simplificadoras ou esquemáticas construídas, inclusive, no seio das teorias sociais dominantes. Nesse sentido, o experimentalismo etnográfico presta-se à construção de discursos contra-hegemônicos, baseados na polissemia e na polifonia das simultâneas representações de um mesmo fenômeno, grupo ou coletividade.

Metodologicamente, o recurso a diferentes vozes é acompanhado da valorização da memória e das biografias ou histórias de vida. A alternativa de etnografias baseadas em vozes encena a ética das relações entre pesquisador e colaborador ou interlocutor, pondo em curso concepções do encontro etnográfico como diálogo, negociação e interlocução culturais. Nesta alternativa, a ética das relações entre pesquisador e pesquisado é erigida, por um lado, a partir do interesse do pesquisador pelos sentidos e significados atribuídos por seu interlocutor à vida social e, por outro lado, na focalização do próprio encontro como processo de conhecimento. Nestas atitudes vislumbra-se uma abertura para considerar o outro como parceiro na construção de interpretações da cultura e para empreender a reflexão sobre as relações de poder entre pesquisador e pesquisado, bem como sobre o sentido ou a utilidade da pesquisa etnográfica para um e outro.

Marcus e Fischer (1986) vêem o experimentalismo etnográfico como uma tentativa da Antropologia cultural de cumprir, com autenticidade, suas promessas de representar as diferenças culturais e de usar o conhecimento como forma de crítica aos nossos modos de viver e de pensar.

É, fundamentalmente, como produtor de conhecimento e de crítica da cultura que o encontro etnográfico se justifica como prática de pesquisa participante.

O texto ou a escrita etnográfica, como já foi sugerido anteriormente, é o meio privilegiado de elaboração e transmissão deste conhecimento e desta crítica, unindo ou estabelecendo as pontes entre os dois momentos essenciais 
da Etnografia: o "estando lá" ou being there que corresponde à situação da pesquisa de campo e o "estando aqui" ou being here que corresponde ao ambiente de "gabinete" em que o pesquisador retoma o contato com seus colegas universitários e escreve o texto que tornará público seu trabalho (Geertz, 1989a; Oliveira, 2000).

A escrita "estando aquil" difere daquela de diários e anotações de campo, pois trata-se da construção propriamente dita de uma interpretação do diálogo, da interlocução que houve "estando lá". Para este momento concorrem tanto a presença da "comunidade de argumentação" da qual faz parte o pesquisador, com seu idioma acadêmico e disciplinar, quanto o compromisso ético, político e epistemológico delicado com a colocação de "vidas alheias" em texto (Oliveira, 2000).

Para Geertz (1989a), não é o excesso de documentação e detalhes ou os argumentos teóricos que atribuem credibilidade ao texto, mas sim, o fato do pesquisador ter estado lá. Em suas palavras:

La habilidad de los antropólogos para hacernos tomar en serio lo que dicen tiene menos que ver con su aspecto factual o su aire de elegancia conceptual, que con su capacidad para convencernos de que lo que dicen es resultado de haber podido penetrar (o, si se prefiere, haber sido penetrado por) outra forma de vida, de haber, de uno o outro modo, realmente "estado allí". Y en la persuasión de que este milagro invisible ha ocorrido, es donde interviene la escritura. (p. 14)

O texto é, até certo ponto, a certificação, por escrito, de algo presenciado e vivido, uma espécie de testemunho único, uma vez que os trabalhos de campo não podem, simplesmente, ser replicados. Mas é, ainda, o próprio trabalho do pensamento, muito mais do que o relatório de dados e conclusões já acondicionadas em algum lugar da mente.

Os textos etnográficos, pensa Geertz (1989a), não podem ser considerados "murmúrios anônimos", como Foucault (1979) entende que sejam os discursos científicos. A tentativa de manter a Antropologia distante da literatura evoca o medo de encarar o caráter literário da escrita etnográfica e a tentativa de fazê-la parecer ser científica. Há, de fato, um incômodo em tentar produzir textos científicos a partir de experiências biográficas. Se os textos literários dependem de quem escreve, quando, onde e para quê, enquanto os 
científicos não, na Etnografia a necessidade de localização do autor faz com ela se aproxime da literatura.

A literatura é, portanto, um paradigma necessário ao texto etnográfico que, como quer Geertz, exibe um caráter híbrido, instalado que está entre a aspiração de criar um estilo, singularizando modos de ver e recortar uma paisagem empírica e intelectual e o desejo de comunicar fatos e idéias, articulando informações. Ao caráter híbrido do texto corresponde a ambivalência do escritor etnográfico.

El problema de la firma, tal como el etnógrafo tiene que afrontarlo, o tal como se enfrenta con el etnógrafo, exige a la vez la actitud olímpica del físico no autorial y la soberana auto-conciencia del novelista hiperautorial, sin permitir caer en ninguno de los dos extremos. (Geertz, 1989a, p. 20)

Ainda, para Geertz, se a pesquisa etnográfica é, como experiência pessoal, o processo por meio do qual o pesquisador busca situar-se entre outros que desconhece e não compreende de partida, o texto, por sua vez, é a tentativa de "formular a base na qual se imagina, sempre excessivamente, estar-se situado" (1989b, p. 23).

Uma condição do trabalho de campo é incorporar o outro e ser incorporado por ele em alguma medida. Na escritura do texto não são só os conteúdos cognitivos do encontro com o outro que voltam, cobrando uma elaboração compreensiva, explicativa ou interpretativa, mas a política e a ética deste encontro, pedindo uma apreensão dos atos e atitudes que, quando embaraçosos do ponto de vista do modelo metodológico, tendem a ser omitidos ou "jogados" para as notas de rodapé, prefácios e posfácios.

A vocação da Etnografia, na atualidade, de construir sentidos para a alteridade, no regime itinerante e precário que caracteriza estes tempos, enseja o próprio experimento da pesquisa como auto-reflexivo e como local de articulação de diferentes mundos e de diferentes identidades/alteridades: como local possível de compreensão de uns diante de outros, do pesquisador diante do interlocutor e, vice-versa, do interlocutor diante do pesquisador. De tal forma que a pesquisa participante e o texto que dela deriva, produzindo efeitos de reconhecimento e desconhecimento de lugares de identidade e alteridade, produzem, também, efeitos de conhecimento no par pesquisador/interlocutor, 
efeitos de conhecimento de si, do outro e do processo de constituição do encontro etnográfico, bem como de sua função ou utilidade para ambos.

Resta pensar de que maneira estas idéias trazidas das matrizes etnográficas servem ao entendimento e à constituição de comunidades interpretativas.

\section{Epistemologia pragmática, pesquisa participante e comunidades interpretativas}

A constituição de sentidos da alteridade, na prática da pesquisa participante, como se viu, encontra-se, na atualidade, muito mais explicitamente definida como resultado do diálogo, da interlocução e da negociação cultural e interpessoal entre pesquisadores e pesquisados. A composição destes campos de pesquisa inclui alteridades próximas e/ou distantes e pesquisadores da Antropologia mas, também, de áreas envolvidas com a pesquisa qualitativa como a Geografia, a História oral, a Sociologia, a Terapia Ocupacional, a Economia, a Psicologia Social, a Psicologia Clínica Social, entre outras.

O encontro etnográfico é, ainda, encontro de diferenças de classe ou posição social, étnicas, de gêneros, geracionais, de pertencimentos socioculturais, de especialidades e saberes.

Assim como se concebe os congressos e encontros científicos como ocasiões para o intercâmbio entre pares, é possível pensar os processos de pesquisa participante como oportunidades de intercâmbio intelectual entre pesquisadores profissionais e indivíduos, grupos ou coletividades próximos ou distantes do ambiente acadêmico.

A crítica do paradigma positivista e da hegemonia do saber científico é condição para a criação e sustentação de comunidades interpretativas das quais façam parte diferentes protagonistas ou sujeitos sociais, entre eles o pesquisador acadêmico ou profissional.

Tomar a pesquisa participante como conjuntura propícia às comunidades interpretativas implica o questionamento das formas de pesquisar em ciências humanas, focalizando a ética e a política das relações entre pesquisador e pesquisado. Este último, o pesquisado, convidado a participar como colaborador e/ou interlocutor. 
Para uma crítica do paradigma positivista em favor das comunidades interpretativas é interessante a proposta de Boaventura de Sousa Santos de uma apreensão hermenêutica da epistemologia e da ciência.

A reflexão hermenêutica, de acordo com este autor:

Visa transformar o distante em próximo, o estranho em familiar, através de um discurso racional (...), orientado pelo desejo de diálogo com o objeto da reflexão para que ele nos fale, numa língua não necessariamente a nossa mas que nos seja compreensível, e nessa medida se nos torne relevante, nos enriqueça e contribua para aprofundar a autocompreensão do nosso papel na construção da sociedade, ou, na expressão cara à hermenêutica, do mundo da vida (Lebenswelt). (Santos, 1989, p. 12)

Uma vez que o discurso científico se tornou mais e mais estranho e distante do senso comum, a reflexão hermenêutica ganha sentido enquanto modo de compreender a ciência como prática social de conhecimento formada no diálogo com o mundo. Ela intervém, também, na desconstrução das imagens que a ciência construiu sobre si mesma.

\section{A reflexão hermenêutica desvela o positivismo lógico como}

o apogeu da dogmatização da ciência que vê nesta o aparelho privilegiado da representação do mundo, sem outros fundamentos que não as proposições básicas sobre a coincidência entre a linguagem unívoca da ciência e a experiência ou observação imediatas, sem outros limites que não os que resultam do estágio do desenvolvimento dos instrumentos experimentais ou lógicos dedutivos. (Santos, 1989, pp. 22-23)

E aponta a epistemologia que, entre os séculos XVII e meados do XIX, consolidou a idéia da ciência como saber privilegiado do qual todos os outros dependiam - inclusive a Filosofia -, em transformação com relação às suas funções na criação de uma consciência científica e às suas "obrigações" para com a justificação da ciência. Se, desde a fundação da ciência moderna, a epistemologia cuidou de justificar a ciência por meio de suas causas, a partir do século XX ela passa a justificar a ciência pelas suas consequiências, ou seja, principalmente pela produção de tecnologia.

É perceptível como, no cotidiano das relações entre especialistas e "leigos" ou nos meios de comunicação de massa, o argumento "da maravilha das criações tecnológicas" é esgrimido contra os questionamentos dirigidos à ciência. 
Esta ênfase na finalidade ou nas conseqüências da ciência se, por um lado, qualifica a crise epistemológica que acompanha a própria crise do paradigma positivista, por outro lado, abre a possibilidade de se avaliar as conseqüências sociais da ciência, pois esta epistemologia incide sobre os utilizadores, destinários, sujeitos ou vítimas destas consequiências.

As consequiências da ciência dizem respeito ao conjunto de cidadãos e não apenas aos cientistas e os primeiros devem adquirir meios e competência para participar do debate sobre os destinos do conhecimento científico. Faz-se necessário, então, o desenvolvimento de uma "pragmática epistemológica", de uma reflexão sobre as conseqüências do conhecimento científico envolvendo destinatários e cientistas.

Para Boaventura de Sousa Santos a hermenêutica, aproximando a ciência da linguagem do dia-a-dia, traduzindo a "anormalidade" dos discursos científicos, conectando interlocutores de diferentes esferas da vida social em torno da produção do conhecimento, é a "pedagogia da construção de uma epistemologia pragmática” (1989, p. 29). A epistemologia pragmática é, por sua vez, a constante reflexão sobre as consequiências do conhecimento, norteando decisões sobre como, o quê e para quê pesquisar.

Na visada hermenêutica, o objetivo da ciência está fora dela, na forma de requisitos éticos e políticos em direção à democratização do saber prático e ao "hábito de decidir bem".

A interiorização destes objetivos é particularmente importante para as ciências sociais, uma vez que a hermenêutica aplicada a estas ciências tem o duplo papel de "tornar compreensível o que as ciências sociais são na sociedade e o que elas dizem sobre a sociedade" (Santos, 1989, p. 14).

Evidencia-se que a dimensão autoreflexiva da pesquisa participante é solidária deste "programa hermenêutico", colaborando para a clarificação e negociação de seus objetivos políticos, bem como assumindo a responsabilidade ética por seus efeitos políticos e ideológicos. Por outro lado, o setting de diálogo e interlocução no qual se dá o trabalho de interpretação dos sentidos das relações sociais é favorável à democratização e ao aprofundamento do saber prático. 
Uma epistemologia pragmática passa, também, ainda de acordo com Boaventura de Sousa Santos, pela ruptura com a ruptura epistemológica que separou ciência e senso comum.

A separação entre ciência e senso comum, entre conhecimento científico e opinião, nas ciências sociais, é representada pela posição de Bachelard (1971, 1972), para quem as ciências sociais deveriam se consolidar contra o senso comum, no espírito da objetivação destas ciências.

O modelo desta objetivação tem uma série de caraterísticas que marcam a prática da pesquisa positivista em ciências humanas: a) transformação da relação eu/tu em relação sujeito/objeto, feita de distância e estranhamento mútuo e de subordinação do objeto ao sujeito; b) crença no conhecimento científico como única forma válida de saber, ancorada na objetividade que separa teoria e prática, ciência e ética; c) redução do universo de observáveis ao universo dos quantificáveis e do rigor do conhecimento ao rigor matemático, desqualificando as qualidades que dão sentido à vida social; d) desconfiança das aparências e desprezo pela comunicação face a face; e) arrogância de só considerar relevante aquilo que se pode conhecer por meio do método científico e recusa a olhar o que não se quer ou se pode conhecer; f) especialização e profissionalização do saber, estabelecendo simbioses entre saber e poder e excluindo os chamados "leigos"; g) racionalidade instrumental irresponsável pelas "aplicações"; h) discurso "rigoroso", destituído de imagens, figuras de linguagem ou metáforas, desencantado, triste e sem imaginação (Santos, 1989).

A reconciliação com o senso comum tem evidentes implicações para uma epistemologia pragmática e, com mais razão, para o reencantamento dos discursos e práticas nas pesquisas dos assuntos humanos. Esta reconciliação depende, contudo, de uma relativização da oposição entre ciência e senso comum e suas respectivas representações cristalizadas pela hegemonia do pensamento científico.

Para as instituições científicas, senso comum, opinião ou consciência coletiva são, num sentido positivo, objetos de estudo da Sociologia e, num sentido negativo, ideologia, falsa consciência, ilusão. Porém, em ambos os casos, a ciência deve construir-se contra os preconceitos, o conservadorismo e a superficialidade que caracterizariam o senso comum. Colocando-se a si 
mesma do lado das luzes, a mentalidade científica esquece que a ciência tanto é perpassada por preconceitos quanto cria, ela mesma, teorias que se consolidam e se perpetuam como uma espécie de status quo acadêmico, veiculando e legitimando preconceitos contra determinados indivíduos, grupos sociais e coletividades.

As representações da oposição entre ciência e senso comum baseiamse na imputação de erro, distorção, irracionalidade, falsidade, enviesamento e todo um elenco de qualidades negativas à consciência coletiva. Uma caracterização alternativa do senso comum interessa à epistemologia pragmática e à formação de comunidades interpretativas. Esta alternativa é apresentada por Boaventura de Sousa Santos em palavras que vale a pena reproduzir:

O senso comum faz coincidir causa e intenção; subjaz-lhe uma visão do mundo assente na ação e no princípio da criatividade e das responsabilidades individuais. O senso comum é prático e pragmático; reproduz-se colado às trajetórias e às experiências de vida de um dado grupo social e nessa correspondência se afirma de confiança e dá confiança. O senso comum é transparente e evidente; desconfia da opacidade dos objetos tecnológicos e do esoterismo do conhecimento em nome do princípio da igualdade do acesso ao discurso, à competência cognitiva e à competência linguística. $\mathrm{O}$ senso comum é superficial porque desdenha das estruturas que estão além da consciência, mas, por isso mesmo, é exímio em captar a profundidade horizontal das relações conscientes entre pessoas e entre pessoas e coisas. O senso comum é indisciplinar e imetódico; não resulta de uma prática especificamente orientada para o produzir; reproduz-se espontaneamente no suceder quotidiano da vida. Por último, o senso comum é retórico e metafórico; não ensina, persuade. (Santos, 1989, p. 40)

Na percepção destas qualidades do senso comum reside a esperança de que ele venha a contribuir para o conhecimento, transformando a ciência e sendo por ela transformado.

$\mathrm{O}$ argumento central do autor que aqui se quer reforçar é aquele que designa a ruptura com a cisão entre senso comum e ciência como modo de inserir a ciência numa totalidade que a transcende, buscando um conhecimento que, "sendo prático não deixe de ser esclarecido e, sendo sábio, não deixe de estar democraticamente distribuído" e procurando atenuar a distância entre verdade científica e verdade social da ciência (Santos, 1989). 
A hermenêutica da epistemologia preocupa-se com a verdade social da ciência para interrogar a verdade científica que se ocupa com a ordem metódica, esquecendo-se da desorganização e da incerteza que provoca nos indivíduos e nas sociedades.

A proposta de uma epistemologia pragmática explicita e nomeia um itinerário familiar à pesquisa participante.

É plausível ler, tanto na Sociologia quanto na Psicologia, o florescimento da pesquisa participante, no interior de metodologias qualitativas emergentes a partir das décadas de 80 e 90, como uma reação ao esgotamento dos métodos quantitativos. Deste ponto de vista, as metodologias qualitativas poderiam ser vistas como dispositivos de crescimento e "aperfeiçoamento" do modelo positivista aplicado às ciências humanas, perseguindo, muitas vezes, a objetividade do conhecimento por meio da abordagem de dimensões da realidade humana esquecidas ou mascaradas pela quantificação.

Se algumas tendências empenham-se na justificação do rigor e da adequação científicos dos métodos qualitativos nas ciências humanas, outras tendem a se envolver com as justificativas éticas, políticas e ideológicas da prática de pesquisa participante. Esta segunda vertente, aproximando-se do método etnográfico que resistiu às exigências de rompimento com o senso comum, adere, em alguma medida, a uma epistemologia pragmática, oferendo exemplos de articulação de saberes especializados e do senso comum e de democratização da produção e transmissão do conhecimento. O compromisso, seja com uma interpretação útil de relações e fenômenos psicossociais, seja com a ação política ou interventiva, é mais um aspecto que ajuda a identificar a pesquisa participante como protótipo de comunidades interpretativas.

\section{Ética e política na pesquisa participante}

$\mathrm{O}$ adjetivo participante de uma pesquisa que se predispõe à formação de comunidades interpretativas remete à discussão sobre papéis e lugares do pesquisador e dos indivíduos e grupos na condição de colaboradores e interlocutores. 
A composição de saberes, a construção de interpretações, a transposição de distâncias sociais, culturais e psicológicas que o diálogo pode produzir dependem das posições dos protagonistas da pesquisa: transformação e confrontação de identidades e alteridades no interjogo de diferenças são a atmosfera do diálogo.

Estas posições resultam da negociação de atitudes e valores e das relações de poder envolvendo a distribuição democrática dos lugares de escuta, fala e ação no decorrer da pesquisa de campo, as formas de apropriação e destinação do saber elaborado e a apreciação de efeitos de dominação e de emancipação do conhecimento e sua divulgação.

No tipo de pesquisa participante a que se quer dar destaque, a interlocução que se estabelece no trabalho de campo tem como horizonte a construção do sentido da experiência de um outro próximo ou distante.

Nesta visão, o interlocutor, representante do "pólo pesquisado", é portador e porta-voz da experiência e o pesquisador pode estar na posição de recolhedor da experiência, mediador, tradutor ou intérprete. No diálogo, contudo, o interlocutor transmite sua experiência, interpretando-a, de tal forma que também funciona como tradutor e mediador de sua posição social, cultural e subjetiva para o pesquisador. O jogo de identidades e alteridades que se dão a conhecer mutuamente, afirmando-se, mas, ainda, deslocando-se e transformando-se, participa da mobilidade destes lugares ou funções de tradução e mediação.

A combinação de interpretações e a composição de saberes nada mais é do que a articulação de pontos de vista, vozes e diferenças tendo em vista a atribuição de sentido àquilo que se investiga, àquilo que justifica a investigação e ao encontro que encarna e realiza suas possibilidades e seus desdobramentos. Neste empreendimento, o pesquisador encarrega-se de tarefas diferenciadas e assume responsabilidades atadas ao fato de ter sido dele, na maioria das vezes, a iniciativa do contato, bem como a proposição inicial de uma pauta de trabalho.

A elaboração de um projeto, a busca de financiamentos, a constituição ou não de equipes de pesquisa, a condução do trabalho de campo, a escolha dos interlocutores no ambiente acadêmico e no campo, a escrita e a divulgação dos textos que abrigam a pesquisa são tarefas do pesquisador. 
A idéia de uma dupla situação da pesquisa etnográfica, tal como considerada por Oliveira (2000) nas figuras do "estar lá" e do "escrever aqui”, auxilia a entender que a função de intérprete do pesquisador faz um percurso diferente daquele de seu interlocutor.

$\mathrm{Na}$ situação de campo, pesquisador e colaborador fazem um esforço intelectual, cognitivo e afetivo de mútua compreensão, negociando a pertinência de determinadas temáticas, aprofundando a exposição de modos de sentir e de pensar, retomando aspectos lacunares, obscuros ou intrigantes dos relatos e das observações e reassentando, sempre que necessário, uma espécie de contrato ou pacto de trabalho compartilhado.

Na situação “de gabinete”, o pesquisador retoma não apenas os registros de campo - anotações de observações e impressões, gravações ou transcrições de relatos orais, fotografias, filmes, documentos -, mas a cena em que uma relação de confiança se estabeleceu e na qual lhe foram confiados modos de pensar, sentir e viver. Nesta cena, atualizam-se compromissos éticos e políticos assumidos, implícita ou explicitamente, com o interlocutor, de tal forma que o planejamento de próximas etapas da pesquisa ou o trabalho de escrita realizam-se sob o impacto desses compromissos.

Enquanto a atividade de mediação e tradução do interlocutor ou colaborador é exercida nas conversações que este mantém com o pesquisador, a do pesquisador estende-se de modo imperativo à escrita. Por isso, a importância do texto como síntese de interpretações e como produtor de efeitos de conhecimento, políticos e ideológicos, uma vez feita a sua divulgação.

O texto escrito consagra interpretações, representações e imagens da alteridade ao mesmo tempo em que, sempre, denuncia a presença do pesquisador como autor.

A assunção de um estilo tem muito a ver com modos de se situar e de elaborar a tensão, antes mencionada, entre o discurso científico e a escrita literária. Mas guarda relações, ainda, com os propósitos ou fins que se espera da divulgação do texto para diferentes leitores em diferentes esferas sociais: a comunidade acadêmica em âmbito local, nacional ou internacional; os grupos sociais pesquisados; instâncias governamentais; o público em geral. 
$\mathrm{Na}$ cena da escrita não são apenas os interlocutores da pesquisa de campo que intervêm com suas demandas de esclarecimento, fidelidade, respeito ou solidariedade às suas formas de vida: a transcrição destas formas de vida, ao ganhar o mundo, ensejam novas interpretações e apropriações cujos efeitos políticos e ideológicos, embora não possam ser planejados ou controlados, precisam ser ponderados ou antevistos pelo pesquisador que, ao fazêlo, direciona sua escrita, fazendo escolhas sobre o quê escrever, como e para quem. Na verdade, a cena da escrita é povoada de leitores virtuais em que se projeta a continuidade de um diálogo expandido.

Não é conveniente subestimar as funções políticas do texto: por um lado, ele expressa a política do trabalho de campo; por outro, ingressa na luta política, servindo, pela natureza de suas representações, à emancipação ou à dominação.

Da perspectiva de uma pesquisa participante que acolhe diferentes vozes e procura o diálogo com saberes advindos da experiência de viver, algumas intenções são mais claramente identificáveis: a construção de representações contra-hegemônicas que podem contribuir para o aprimoramento mútuo das ciências humanas e do senso comum, como quer Boaventura de Sousa Santos, na medida em que promovem a crítica tanto das concepções dogmáticas e excessivamente generalizantes que formam uma espécie de senso comum das ciências humanas, quanto das representações estigmatizantes e preconceituosas, origem de sofrimento para indivíduos, grupos e sociedades; a atribuição de espessura a "objetos de estudo" tais como a violência, o desemprego, o sofrimento ou a loucura, os movimentos sociais, enfim, os objetos das ciências humanas; o apoio para a ação política de grupos organizados; o subsídio para políticas públicas nas áreas sociais.

Como ensaios ou exercícios de comunidades interpretativas, a pesquisa participante, na questão da autoria, contém, virtualmente, a co-autoria.

No momento da pesquisa de campo, a co-autoria é francamente admitida, incluindo, em muitos casos, a revisão conjunta, pesquisador e interlocutor, das transcrições de relatos orais, das observações de campo e de textos interpretativos. A atribuição de créditos, por ocasião das publicações, aos colaboradores "leigos", bem como o uso dos nomes próprios de narradores e interlocutores, sempre que possível, indicam que a co-autoria pode se afirmar como uma consequiência mais radical da pesquisa como diálogo. 
Paralelamente, diferentes formas de divulgação dos trabalhos de pesquisa participante apontam, também, na direção de uma democratização do conhecimento, abrindo a possibilidade de colaborações diferenciadas na produção de textos com diferentes linguagens e destinatários ou de outros objetos culturais como um documentário, uma peça teatral ou uma exposição.

O valor formativo e libertário do conhecimento cresce na medida da democratização de sua construção, divulgação e apropriação, ou seja, na medida em que é concebido por e para coletivos dos quais participam uns e outros na perspectiva de alcançar um bem comum. A renovação das ciências humanas parece mesmo depender da ruptura com a assepsia metodológica do paradigma positivista e da superação da dominação do saber científico em relação a outros saberes. A democratização da universidade, por sua vez, pode se beneficiar da crítica epistemológica e metodológica que revê os modos de pesquisar e seus sentidos. A pesquisa participante, neste cenário, representa um caminho ou uma via de aprofundamento desta renovação, pois, buscando o sentido da alteridade, predispõe-se à auto-reflexão.

Schmidt, M.L. S. (2006). Participative research: Alterity and interpretative communities. Psicologia USP, 17(2), 11-41.

\begin{abstract}
This article presents a set of problems led to research, which seeks the cooperation of individuals, groups and community groups, whose experience, personal and collective, we want to know. Based on ethnographic standards of the participative research on anthropology, it focuses on the field research policy and ethics as an identities/ alterities dialog and their nexus with the construction of interpretative communities.
\end{abstract}

Index terms: Participant research. Ethnography. Alterity. Interpretative communities. 
Schmidt, M. L. S. (2006). Recherche participante: altérité et communautés interprétatives. Psicologia USP, 17(2), 11-41.

Résumé: Cet article présente un ensemble de problèmes à la recherche qui poursuit la collaboration des individus, des groupes et des collectivités dont expérience, personnelle et collective, on veut connaître. S'appuyant sur les matrices ethnographiques de la recherche participante dans le champ d'anthropologie, l'article focalise la politique et l'éthique de la recherche de champ comme dialogue des identités/altérités et ses liens avec la constitution des communautés interprétatives.

Mots-clés: Recherche participante. Ethnographie. Altérité. Communautés interprétatives.

\section{Referências}

Augé, M. (1994). Não lugares: introdução a uma antropologia da supermodernidade. Campinas, SP: Papirus.

Augé, M. (1997). Por uma antropologia dos mundos contemporâneos. Rio de Janeiro: Bertrand Brasil.

Bachelard, G. (1971). Le nouvel esprit scientifique. Paris: PUF.

Bachelard, G. (1972). La formation de l'esprit scientifique. Paris: J. Vrin.

Brandão, C. R. (Org.). (1999). Repensando a pesquisa participante. São Paulo: Brasiliense.

Clifford, J. (2002). A experiência etnográfica: antropologia e literatura no século XX. Rio de Janeiro: Ed. UFRJ.

Foucault, M. (1979). What is an author? In J. V. Harari (Ed.), Textual strategies. New York: Ithaca.

Geertz, C. (1989a). El antropologo como autor. Barcelona, España: Paidos.

Geertz, C. (1989b). A interpretação das culturas. Rio de Janeiro: Livros Técnicos e Científicos.

Griaule, M. (2000). Dios de agua. Barcelona, España: Editorial Alta Fulla.

Malinowski, B. (n.d.). Um diário no sentido estrito do termo. Rio de Janeiro: Record.

Malinowski, B. (1978). Argonautas do Pacífico Ocidental: um relato do empreendimento e da aventura dos nativos nos arquipélagos da Nova Guiné melanésia (Série Os Pensadores). São Paulo: Abril Cultural. 
Marcus, G. E. (1998). Ethnography through thick \& thin. New Jersey: Princenton University Press.

Marcus, G. E., \& Fischer, M. M. J. (1986). Anthropology as cultural critique: An experimental moment in the human sciences. Chicago: The University of Chicago Press.

Oliveira, R. C. de. (2000). O trabalho do antropólogo (2a ed.). Brasília, DF: Paralelo 15.

Rocha, M. L. da, \& Aguiar, K. F. de. (2003). Pesquisa-intervenção e a produção de novas análises. Psicologia: Ciência e Profissão, 23(4), 64-72.

Santos, B. de S. (1989). Introdução a uma ciência pós-moderna. Rio de Janeiro: Graal.

Santos, B. de S. (1999). Da ideia de universidade à universidade de ideias. Pela mão de Alice: o social e o político na pós-modernidade. São Paulo: Cortez.

Santos, B. de S. (2004). A universidade no século XXI: para uma reforma democrática e emancipatória da universidade. São Paulo: Cortez.

Thiollent, M. (1999). Notas para o debate sobre pesquisa-ação. In C. R. Brandão (Org.), Repensando a pesquisa participante (pp. 82-103). São Paulo: Brasiliense.

Recebido em: 19.10.2005

Aceito em: 20.11.2005 